\title{
Removal of High Density Impulse Noise using Efficient Median Filter for Digital Image
}

\author{
Trapti Soni \\ M.Tech Student, Dept. of CSE \\ Sanghavi Institute of Management \& Science, \\ Indore \\ R.G.P.V. University, Bhopal (M.P.)
}

\author{
Narendra Rathor \\ Asst. Professor, Dept. of CSE \\ Sanghavi Institute of Management and Science, \\ Indore \\ R.G.P.V. University, Bhopal (M.P.)
}

\begin{abstract}
An Efficient Median Filter (EMF) algorithm for removal or enhancement of gray scale images are highly corrupted impulse noise is proposed in this paper. Noise in image are represent the pixel value 0 's and 255's are ensures that black and white dot in image. In proposed algorithm take an image and select $3 \times 3$ size window and target or center pixel value check if its value is 0 's or 255's then image is corrupted otherwise noise free image. If image is noisy and target pixels neighboring pixel value is between 0 's and 255 's then we replace pixel value with the median value and if target pixels neighboring pixel value is 0 's or 255's then we replace pixel value with the mean value. Else increased the window size and again repeat this process until image is denoised. The proposed filter algorithm shows better simulation result as compare the existing algorithms. The simulation result shows better and efficient performance of PSNR and MSE and computation time.
\end{abstract}

\section{Keywords}

Impulse Noise, Digital Image, Median Filter, PSNR and MSE.

\section{INTRODUCTION}

The field of digital image processing refers to processing digital images by means of a digital computer. Image processing is widely used in many fields, such as industrial inspection, satellite imaging, medical imaging, telecommunication, cinema, scientific visualization; law enforcement etc. digital images are two types such as vector image and digital image. Vector images made up of vectors which lead through locations called control points. Each of these points has defined on $\mathrm{x}$ and $\mathrm{y}$ axes of the work plain and Digital image are 2-D array of real numbers.2-D image is divided into $\mathrm{N}$ rows and $\mathrm{M}$ columns, the intersection of these rows and columns is known as pixels. In this paper we use digital images [1]

Images are often corrupted by impulse noise Image noise is any degradation in an image signal while an image is being sent from one place to another place via satellite, wireless and network cable etc. error occurs in image signal while an image is being sent electronically from one place to another place, for example an image transmitted using a wireless network might be corrupted as a result of lighting or other atmospheric disturbance[2].Impulse noise are classified into two categories: fixed valued impulse noise and random valued impulse noise. Impulse noise the pixel value of a noisy pixel takes either maximum or minimum gray level [3]. Gray scale images are distinct from one -bit black and white images, which in the context of computer imaging are images with only the two colors, black and white (also known as binary images). Gray scale images have many shades of gray in between 0 and 255[4]. In random value impulse noise, noisy pixel value is in the range of $[0,255]$ for gray scale images. In this paper we focus only on removing fixed value impulse noise.

\section{LITERATURE SURVEY AND RELATED WORK}

Removing impulse noise there are many linear and non linear filtering techniques.

In Median filter (MF) [5] is used to reducing noise. It is used to remove noise in image for only low noise density. This filter performance is poor. The Standard Median Filter (SMF) is used to remove only low noise densities but high noise densities its performance is poor and image is not cleared.

In Adaptive Median Filter (AMF) [6] [25] "Salt \& Pepper Impulse Detection and Median based Regularization using Adaptive Median Filter". New Adaptive 2D spatial filter operators for the restoration of salt \& pepper impulse noise are corrupted digital images. Its performance is better as compare to SMF but high noise densities the window size has to be increased, so images are blurring.

Weighted Median Filter (WMF) [7] is also used to removal salt and pepper noise and its performance is good for low density noise but high density noise images are not clear.

In Center Weighted Median Filter (CWMF) [8][9] weights are assigned to selected pixels in the filtering window in order to control the filtering behavior but at high noise density filters fails to reproduce the original image with edge details[10]. Centre weighted median filter and Recursive Weighted Median Filter (RWMF) are used to improve the performance of the median filter. It also give more weight to some selected pixel in window and exhibits blurring of filtered images [11] [12] [13].To overcome this problem in Adaptive Center Weighted Median Filter (ACWMF) but in this filter we need some threshold values [5] [14].

To remove the threshold problem in Tri-State Median Filter (TSMF)[14][15].In this filter images noise detection by an impulse detector, this takes the outputs from the SMF and CWMF and compare with the centre pixel value and origin value in order to make a tri-state decision. The switching logic is controlled by a threshold T and the output of TSM filter [16] [17].

Directional Weighted Median Filter (DWMF), are used to remove impulse noise and this filter is also used to identify noisy pixel using all four directional information of the selected pixel to calculate the median. In this method, two major steps: Detect noisy pixel using new impulse detector and Utilize weighted directional calculate the median for removing impulse noise and preserve details [18] [19]. 
Decision Based Algorithm (DBA) is also known as Switching Median Filter (SMF) [19]. In this filter is used to minimize the undesired alteration of uncorrupted pixels by the filter. Overcome this problem, switching median filter checks each input pixel whether it has been corrupted by impulse noise or not. Then it will be change only the intensity of noisy pixel candidates, while left the other pixels unchanged the decision is based on a threshold value. This filter repeated replacement of neighboring pixel produces streaking effect [20].

In Decision Based Unsymmetrical Trimmed Median Filter (DBUTMF) is used to overcome streaking effect problems, but the trimmed median of the $3 \times 3$ window will not provide the best result for the noisy pixel [21].

In Modified Decision Based Unsymmetrical Trimmed Filter (MDBUTMF) is used to remove image details such as thin lines and corners while problem of DBUTMF, But in this filter performance is not best [22].

Modified Non-Linear Filter (MNLF) is also used to remove impulse noise. In this method the noisy pixel are replaced by trimmed median value when other pixel are not all 0 's or $255^{\prime} \mathrm{s}$. But if the all the pixel value are 0 or 255 then this method increases the window size and then trimmed median value is calculated and noisy pixel is replaced [23] [24].

Other methods are different thoughts such as. In Cloud Model (CM) [26] is also remove impulse noise and it is established the relationship between the randomness and fuzziness. $\mathrm{CM}$ is the uncertainty transformation between quantitative representation and qualitative concept based on normal distribution and bell shaped membership function. Opening-Closing Sequence (OCS) filter [27] is used to estimate the intensity values of noisy pixel. It is based on the mathematical morphology.

In Decision-based Average or Median filter (DAM) [28] Combine the advantages of the [29] and adaptive median filter in order to achieve better result. DAM has a good trade-off between quantitative and qualitative properties of the recovered image and computation time. And this method noisy pixel values are replaced by average and median of the neighbour's value.

Edge-Preserving Algorithm (EPA) [30] is also used for remove impulse noise and it is used a directional correlation dependent Filtering technique, Switching-based Adaptive Weighted Mean filter (SAWM) [31] is the weighted average filtering technique. It is used to remove impulse noise with the help of weighted mean of nearest uncorrupted pixels value are replaced by noisy pixel. Adaptive Iterative Mean (AIM) filter is alters the corrupted pixels in a different number of iterations according to their Euclidean distance from the nearest uncorrupted pixel. It is fast and quit real time application [32].

All this filters fail at low and high noise density. The proposed filter achieves best performance value of Peak Signal to noise ratio (PSNR) and MSE values.

\section{PROPOSED FILTER}

The proposed Median filter is a simple and powerful nonlinear filter. It is used for reducing the amount of intensity variation between one pixel and the other pixel. In this filter, if image is noisy and target pixels neighboring pixel value is between 0's and 255's then we replace pixel value with the median value. The median is calculated by first sorting all the pixel values into ascending order and then replace the pixel being calculated with the target pixel value salt and pepper noise. And if target pixels neighboring pixels value is 0 's or 255 's then we replace pixel value with the mean value. The mean is calculated by first sorting all the pixel values into ascending order and then replace the pixel being calculated with the target pixel value salt and pepper noise. Else increased the window size and again repeat this process until image is denoised. In fig. 1 block diagram is show proposed algorithm which is cleared specify work in this algorithm for remove impulse noise.

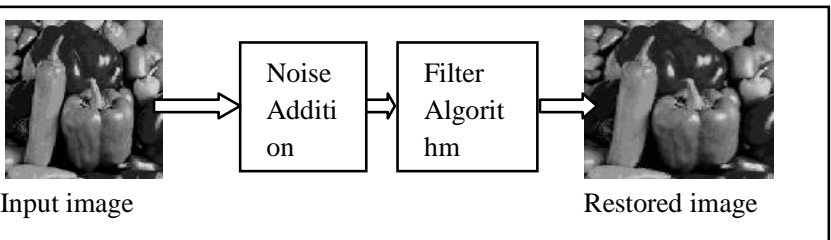

Fig 1: Block diagram of proposed filter

\section{PROPOSED FILTER ALGORITHM}

STEP 1:- Initial step: -Read the image.

STEP 2:- Condition Noise Detection

If $0<\mathrm{Y}(\mathrm{i}, \mathrm{j})<255 /$ Noise free

Then, Send to de-noised or restore

STEP 3:- Select a small 3X3 size window with target pixel Y. Check the pixels values

STEP 4:- Apply Condition

Case 1: If target pixel $\mathrm{Y}(\mathrm{i}, \mathrm{j})$ neighboring all pixels are 0's or 255's then go to step 5 / Noise Removal

Case 2: if target pixel $\mathrm{Y}(\mathrm{i}, \mathrm{j})$ neighboring all pixels are combinations of 0 's and 255's then / Removal of Noise Go to step 6 .

STEP 5:- Take all neighboring pixel values instead of target pixel $Y(i, j)$,after that arrange in ascending order and take the mean of all neighboring values .This mean value is replace by target pixel Y $(i, j)$ value. Now go to step 7.

STEP 6:- Take all neighboring pixel values instead of target pixel $Y(i, j)$, after that arrange in ascending order and take the mean of all neighboring values.This median value is replace by target pixel Y $(i, j)$ value. Now go to step 7.

STEP 7:- de-noised image. Pixels are restored.

\section{METHODOLOGY OF PROPOSED WORK}

The proposed Median Filter Algorithm was processes to detect noise and remove $100 \%$ noise in given image as compare to previous algorithm.

Ex: - CASE1: If target pixel y $(i, j)$ value is maximum (i.e.255) gray level and its neighboring pixel are also maximum value or salt noise.

To remove the salt noise there are two phases 
1) If we take median value it will be 255 , which is again noisy pixel.

2) 5.1.2 If we take mean value it will be 255 , which is also noisy pixel again.

To solve this problem the target pixel is replace by the pepper noise mean value.

$\left[\begin{array}{lll}255 & 255 & 255 \\ 255 & 255 & 255 \\ 255 & 255 & 255\end{array}\right]$

CASE 2:- If target pixel y $(i, j)$ value is minimum (i.e.0) gray level and its neighboring pixel are also minimum value or salt noise.

To remove the salt noise there are two phases

1) 5.2.1 If we take median value it will be 0 , which is again noisy pixel.

2) 5.2.2 If we take mean value it will be 0 , which is also noisy pixel again.

To solve this problem the target pixel is replace by the salt noise mean value.

$$
\left[\begin{array}{lll}
0 & 0 & 0 \\
0 & 0 & 0 \\
0 & 0 & 0
\end{array}\right]
$$

CASE 3:- if target pixel value in selected window is $\max / \mathrm{min}$ gray level $(0 / 255)$ and neighboring pixel contains all that adds 0 and 255 to the image.

To remove noise use following steps:

1) Take the selected window $3 \times 3$ all pixel value instead of target pixel in1-D array.

[255, 0, 255, 0, 255, 255, 0, 255]

2) Now this array element is sorting in ascending order.

$$
[0,0,0,255,255,255,255,255]
$$

3) Now we find the mean value of this array is 159 .

4) Hence replace the target pixel value by 159 .

$$
\left[\begin{array}{ccc}
255 & 0 & 255 \\
0 & 0 / 255 & 255 \\
255 & 0 & 255
\end{array}\right]
$$

CASE 4:-If target pixel value is maximum (i.e.255) or minimum (i.e.0) gray level and its neighbor some pixel contains salt and pepper noise to the image.

In this case to remove noise use following steps:

1) Take the selected window $3 \times 3$ all pixel value instead of target pixel in1-D array.

$[70,80,85,40,0,255,50,255]$

2) Now these array elements is sorting in ascending order and also remove salt and pepper value.

$[40,50,70,80,85]$

3) Now we find the median value of this array is 70 .

4) Hence replace the target pixel value by 70 .

$$
\left[\begin{array}{ccc}
70 & 80 & 85 \\
40 & 255 & 0 \\
255 & 50 & 255
\end{array}\right]
$$

CASE 5:-If the target pixel value in selected window is noise free value, so it does not require for processing.

$$
\left[\begin{array}{lll}
50 & 70 & 90 \\
10 & 80 & 40 \\
60 & 30 & 20
\end{array}\right]
$$

\section{SIMULATION RESULT}

The performance of proposed filter is comparison of different existing algorithm for Barbara gray scale image for low (10\%) to high $(90 \%)$ noise density and tested different gray scale images. For simulation MATLAB R2012b and 8.1 Software are used. The simulation performance The PSNR and MSE (Mean Square Error) can be expressed as:

Performance parameter: - For comparing original image and filtered image, we calculate following parameters:

1. Peak Signal to Noise Ratio (PSNR):-signal to noise ratio is defined by the power ratio between a signal and the background and noise. Where $\mathrm{P}$ is an average power. Both noise and power must be measured at the same points in a system, and within system with same bandwidth.

$$
P S N R=10 \log _{10} \frac{(255)^{2}}{M S E}
$$

2. Mean Square Error (MSE):- The MSE is the cumulative square error between the encoded and the original image defined by: Where, $f$ is the original image and $g$ is the filtered image. The dimension of the image is $\mathrm{m} \mathrm{x} \mathrm{n}$. Thus MSE should be as low as possible for effective filtering.

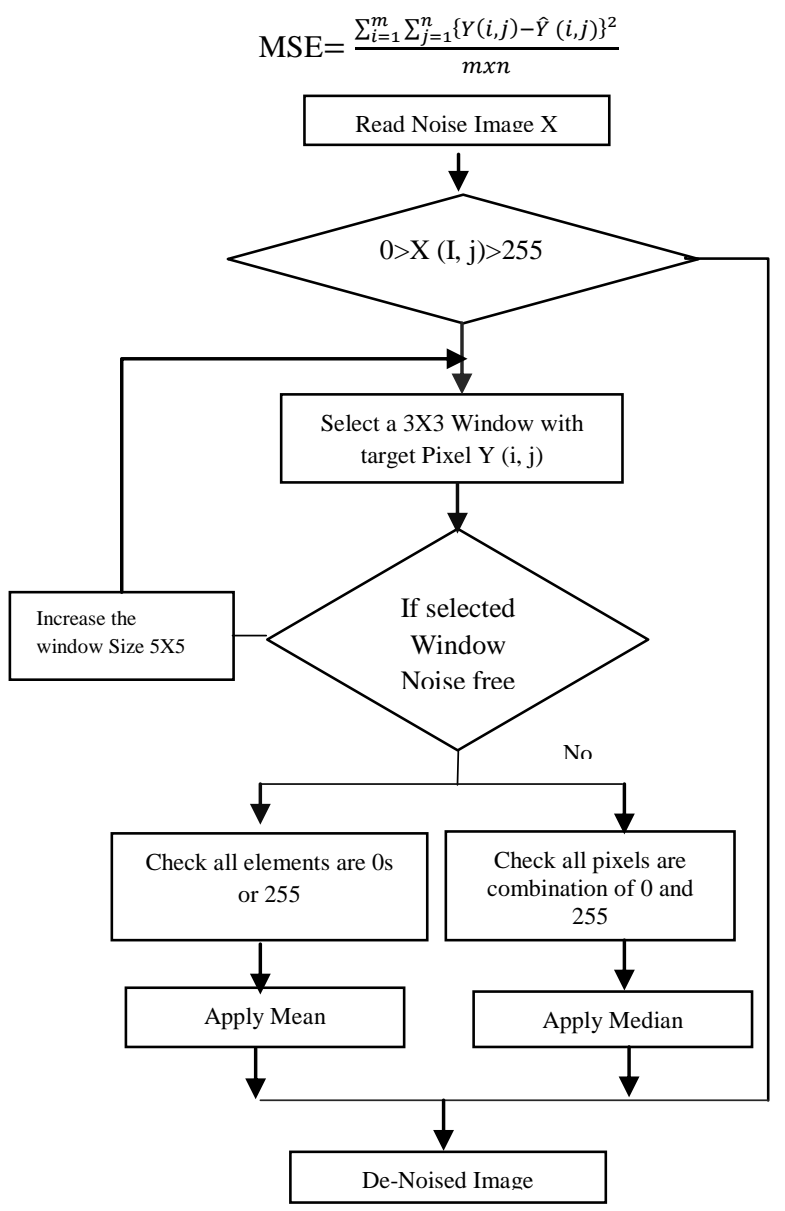

Fig 2: Flow Chart of Proposed Filter 


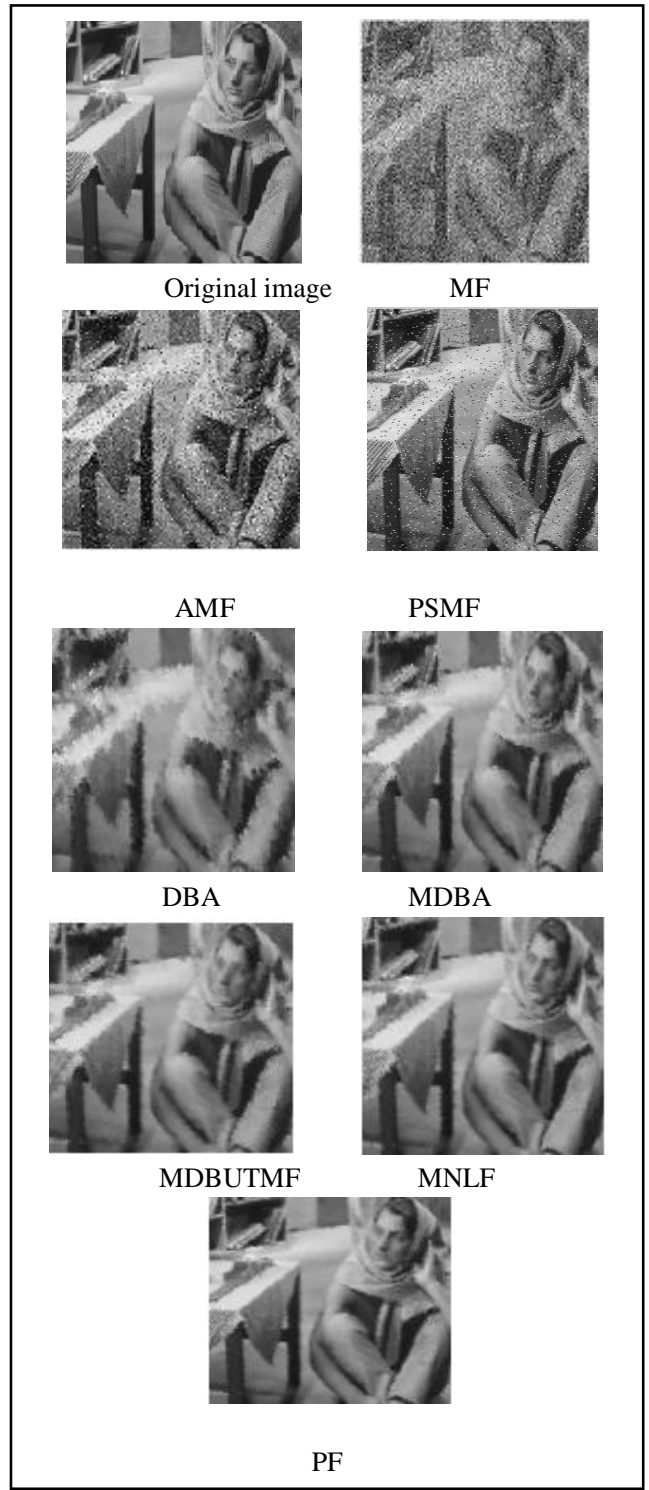

Fig 3: Restored results of different methods for Barbara image corrupted with $60 \%$ Noise density impulse noise

The performance of restored results of different methods for Barbara image which is corrupted by $60 \%$ noise density for impulse noise as show in figure 3 :
Table 1: Comparison results for PSNR of different methods for Barbara image of impulse noise

\begin{tabular}{|c|c|c|c|c|c|c|c|c|}
\hline \multirow[b]{2}{*}{$\begin{array}{l}\text { Noise } \\
\text { Densit } \\
\text { y \% }\end{array}$} & \multicolumn{8}{|c|}{ PSNR } \\
\hline & MF & $\begin{array}{l}\text { PS } \\
\text { M } \\
\text { F }\end{array}$ & $\begin{array}{l}\mathrm{A} \\
\mathrm{M} \\
\mathrm{F}\end{array}$ & $\begin{array}{l}\mathrm{DB} \\
\mathrm{A}\end{array}$ & $\begin{array}{l}\text { MDB } \\
\mathrm{A}\end{array}$ & $\begin{array}{l}\text { MDB } \\
\text { UTM } \\
\text { F }\end{array}$ & $\begin{array}{l}\mathrm{MNL} \\
\mathrm{F}\end{array}$ & $\mathrm{PF}$ \\
\hline 10 & $\begin{array}{l}28 . \\
493 \\
8\end{array}$ & $\begin{array}{l}30 . \\
64 \\
94\end{array}$ & $\begin{array}{l}21 . \\
98 \\
45\end{array}$ & $\begin{array}{l}36 . \\
756 \\
5\end{array}$ & $\begin{array}{l}36.756 \\
9\end{array}$ & $\begin{array}{l}38.12 \\
9\end{array}$ & $\begin{array}{l}37.34 \\
89\end{array}$ & $\begin{array}{l}40.72 \\
64\end{array}$ \\
\hline 20 & $\begin{array}{l}25 . \\
754 \\
2\end{array}$ & $\begin{array}{l}28 . \\
20\end{array}$ & $\begin{array}{l}21 . \\
92 \\
97\end{array}$ & $\begin{array}{l}33 . \\
260 \\
6\end{array}$ & $\begin{array}{l}33.260 \\
7\end{array}$ & $\begin{array}{l}34.60 \\
05\end{array}$ & $\begin{array}{l}34.23 \\
58\end{array}$ & $\begin{array}{l}37.59 \\
71\end{array}$ \\
\hline 30 & $\begin{array}{l}21 . \\
846 \\
5\end{array}$ & $\begin{array}{l}25 . \\
55 \\
9\end{array}$ & $\begin{array}{l}21 . \\
47 \\
35\end{array}$ & $\begin{array}{l}30 . \\
565 \\
9\end{array}$ & $\begin{array}{l}30.530 \\
8\end{array}$ & $\begin{array}{l}32.14 \\
27\end{array}$ & $\begin{array}{l}32.14 \\
12\end{array}$ & $\begin{array}{l}35.45 \\
50\end{array}$ \\
\hline 40 & $\begin{array}{l}18 . \\
407 \\
6\end{array}$ & $\begin{array}{l}22 . \\
69 \\
09\end{array}$ & $\begin{array}{l}21 . \\
47 \\
35\end{array}$ & $\begin{array}{l}28 . \\
260 \\
9\end{array}$ & $\begin{array}{l}28.298 \\
1\end{array}$ & $\begin{array}{l}32.08 \\
86\end{array}$ & $\begin{array}{l}30.57 \\
96\end{array}$ & $\begin{array}{l}33.77 \\
69\end{array}$ \\
\hline 50 & $\begin{array}{l}14 . \\
734\end{array}$ & $\begin{array}{l}19 . \\
44 \\
25\end{array}$ & $\begin{array}{l}20 . \\
65 \\
42\end{array}$ & $\begin{array}{l}26 . \\
284 \\
6\end{array}$ & $\begin{array}{l}26.250 \\
3\end{array}$ & $\begin{array}{l}28.21 \\
75\end{array}$ & $\begin{array}{l}29.00 \\
56\end{array}$ & $\begin{array}{l}31.64 \\
07\end{array}$ \\
\hline 60 & $\begin{array}{l}12 . \\
234 \\
8\end{array}$ & $\begin{array}{l}12 . \\
85 \\
11\end{array}$ & $\begin{array}{l}18 . \\
40 \\
92\end{array}$ & $\begin{array}{l}24 . \\
536 \\
1\end{array}$ & $\begin{array}{l}24.632 \\
1\end{array}$ & $\begin{array}{l}26.59 \\
37\end{array}$ & $\begin{array}{l}27.82 \\
4\end{array}$ & $\begin{array}{l}29.82 \\
00\end{array}$ \\
\hline 70 & $\begin{array}{l}9.9 \\
837\end{array}$ & $\begin{array}{l}10 . \\
52 \\
06\end{array}$ & $\begin{array}{l}14 . \\
85 \\
64\end{array}$ & $\begin{array}{l}22 . \\
779 \\
8\end{array}$ & $\begin{array}{l}22.933 \\
8\end{array}$ & $\begin{array}{l}24.38 \\
59\end{array}$ & $\begin{array}{l}26.05 \\
41\end{array}$ & $\begin{array}{l}27.61 \\
53\end{array}$ \\
\hline 80 & $\begin{array}{l}8.0 \\
229\end{array}$ & $\begin{array}{l}8.4 \\
84 \\
9\end{array}$ & $\begin{array}{l}11 . \\
29 \\
68\end{array}$ & $\begin{array}{l}20 . \\
144 \\
1\end{array}$ & $\begin{array}{l}20.409 \\
8\end{array}$ & $\begin{array}{l}22.01 \\
01\end{array}$ & $\begin{array}{l}24.32 \\
91\end{array}$ & $\begin{array}{l}24.86 \\
03\end{array}$ \\
\hline 90 & $\begin{array}{l}6.5 \\
759\end{array}$ & $\begin{array}{l}6.7 \\
84 \\
7\end{array}$ & $\begin{array}{l}8.0 \\
60 \\
3\end{array}$ & $\begin{array}{l}17 . \\
120 \\
5\end{array}$ & $\begin{array}{l}17.224 \\
2\end{array}$ & $\begin{array}{l}17.98 \\
65\end{array}$ & $\begin{array}{l}21.32 \\
5\end{array}$ & $\begin{array}{l}21.14 \\
21\end{array}$ \\
\hline
\end{tabular}

The simulation results for PSNR (Peak Signal to Noise Ratio) are show in table 1 for different methods of low (10\%) level noise to high $(90 \%)$ level noise density for Barbara image. Comparison results for PSNR of different methods for Barbara image of impulse noise

The comparison chart of PSNR values of different methods for Barbara image for different noise density $(10 \%-90 \%)$ of impulse noise are show in this figure: 


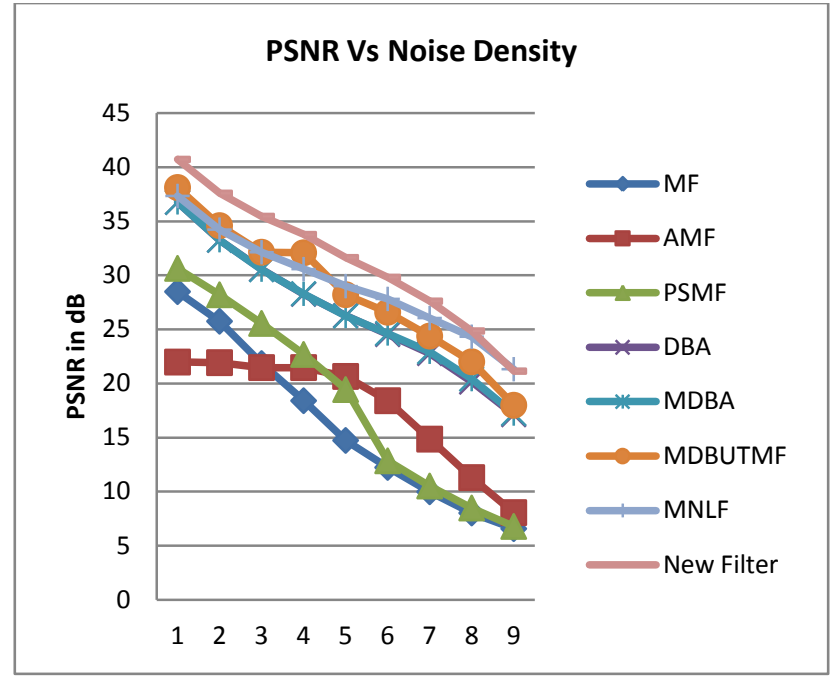

Fig 4: Comparison chart of PSNR of different methods for Barbara image

The simulation results for MSE (Mean Square Error) are show in following table 2 for different methods of impulse noise at low $(10 \%)$ level noise to high $(90 \%)$ level noise density for Barbara image.

Table 2: Comparison results for MSE and computation time (CT) of different methods for Barbara image

\begin{tabular}{|c|c|c|c|c|c|c|c|c|c|c|}
\hline \multirow{3}{*}{$\begin{array}{l}\text { Nois } \\
\mathrm{e} \\
\text { Den } \\
\text { sity } \\
\%\end{array}$} & \multicolumn{10}{|c|}{ MSE and CT } \\
\hline & \multicolumn{2}{|c|}{$\mathrm{AMF}$} & \multicolumn{2}{|c|}{ SMF } & \multicolumn{2}{|c|}{ DBA } & \multicolumn{2}{|c|}{$\begin{array}{l}\text { DBUTM } \\
\text { F }\end{array}$} & \multicolumn{2}{|c|}{$\mathrm{PF}$} \\
\hline & $\begin{array}{l}\mathrm{M} \\
\mathrm{SE}\end{array}$ & CT & $\begin{array}{l}\mathrm{M} \\
\mathrm{SE}\end{array}$ & $\mathrm{CT}$ & $\begin{array}{l}\text { M } \\
\text { SE }\end{array}$ & $\mathrm{CT}$ & $\begin{array}{l}\mathrm{M} \\
\mathrm{SE}\end{array}$ & $\mathrm{CT}$ & $\begin{array}{l}M \\
S \\
E\end{array}$ & $\begin{array}{l}\mathrm{C} \\
\mathrm{T}\end{array}$ \\
\hline 10 & $\begin{array}{l}50 . \\
01\end{array}$ & $\begin{array}{l}64 . \\
15\end{array}$ & $\begin{array}{l}54 . \\
34\end{array}$ & 1.9 & $\begin{array}{l}38 . \\
5\end{array}$ & $\begin{array}{l}6.5 \\
3\end{array}$ & $\begin{array}{l}4.5 \\
6\end{array}$ & 5.7 & $\begin{array}{l}5 . \\
5 \\
0\end{array}$ & $\begin{array}{l}12 \\
.5 \\
2\end{array}$ \\
\hline 20 & $\begin{array}{l}50 . \\
01\end{array}$ & $\begin{array}{l}64 . \\
15\end{array}$ & $\begin{array}{l}54 . \\
34\end{array}$ & 1.9 & $\begin{array}{l}38 . \\
5\end{array}$ & $\begin{array}{l}6.5 \\
3\end{array}$ & $\begin{array}{l}10 . \\
5\end{array}$ & 5.7 & $\begin{array}{l}1 \\
1 . \\
3\end{array}$ & $\begin{array}{l}6 . \\
37\end{array}$ \\
\hline 30 & $\begin{array}{l}55 . \\
66\end{array}$ & $\begin{array}{l}66 . \\
15\end{array}$ & $\begin{array}{l}63 . \\
54\end{array}$ & 2.1 & $\begin{array}{l}45 . \\
55\end{array}$ & $\begin{array}{l}6.5 \\
6\end{array}$ & $\begin{array}{l}17 . \\
12\end{array}$ & 5.9 & $\begin{array}{l}1 \\
8 . \\
5 \\
1\end{array}$ & $\begin{array}{l}7 . \\
74\end{array}$ \\
\hline 40 & $\begin{array}{l}60 . \\
56\end{array}$ & $\begin{array}{l}67 . \\
5\end{array}$ & $\begin{array}{l}72 . \\
34\end{array}$ & 2.5 & $\begin{array}{l}50 . \\
1\end{array}$ & $\begin{array}{l}7.5 \\
9\end{array}$ & $\begin{array}{l}30 . \\
4\end{array}$ & 6.9 & $\begin{array}{l}2 \\
7 . \\
2 \\
5\end{array}$ & $\begin{array}{l}7 . \\
42\end{array}$ \\
\hline 50 & $\begin{array}{l}75 . \\
5\end{array}$ & $\begin{array}{l}67 . \\
15\end{array}$ & $\begin{array}{l}79 . \\
54\end{array}$ & 2.7 & $\begin{array}{l}55 . \\
5\end{array}$ & $\begin{array}{l}7.8 \\
8\end{array}$ & $\begin{array}{l}45 . \\
5\end{array}$ & 6.9 & $\begin{array}{l}4 \\
4 . \\
5 \\
6\end{array}$ & $\begin{array}{l}9 . \\
07\end{array}$ \\
\hline 60 & $\begin{array}{l}80 . \\
65\end{array}$ & $\begin{array}{l}67 . \\
9\end{array}$ & $\begin{array}{l}80 . \\
34\end{array}$ & 2.8 & $\begin{array}{l}60 . \\
1\end{array}$ & 8.1 & $\begin{array}{l}67 . \\
4\end{array}$ & $\begin{array}{l}6.1 \\
0\end{array}$ & $\begin{array}{l}6 \\
7 . \\
7 \\
7\end{array}$ & $\begin{array}{l}8 . \\
72\end{array}$ \\
\hline
\end{tabular}

\begin{tabular}{|l|l|l|l|l|l|l|l|l|l|l|}
\hline 70 & $\begin{array}{l}82 . \\
5\end{array}$ & $\begin{array}{l}68 . \\
5\end{array}$ & $\begin{array}{l}89 . \\
34\end{array}$ & 2.9 & $\begin{array}{l}70 . \\
71\end{array}$ & $\begin{array}{l}8.3 \\
3\end{array}$ & $\begin{array}{l}71 . \\
5\end{array}$ & $\begin{array}{l}6.1 \\
2\end{array}$ & $\begin{array}{l}1 \\
1 \\
2 .\end{array}$ & $\begin{array}{l}9 . \\
43\end{array}$ \\
\hline 80 & $\begin{array}{l}24 \\
4\end{array}$ & $\begin{array}{l}68 . \\
5\end{array}$ & $\begin{array}{l}28 \\
9.5\end{array}$ & 2.9 & $\begin{array}{l}12 \\
4.2\end{array}$ & $\begin{array}{l}8.3 \\
3\end{array}$ & $\begin{array}{l}11 \\
8.9\end{array}$ & $\begin{array}{l}6.1 \\
2\end{array}$ & $\begin{array}{l}2 \\
1\end{array}$ & $\begin{array}{l}10 \\
.4 \\
2\end{array}$ \\
\hline 90 & $\begin{array}{l}10 \\
45 .\end{array}$ & $\begin{array}{l}69 . \\
43\end{array}$ & $\begin{array}{l}80 \\
24 . \\
4\end{array}$ & $\begin{array}{l}2.9 \\
8\end{array}$ & $\begin{array}{l}89 \\
4.2\end{array}$ & $\begin{array}{l}9.1 \\
4\end{array}$ & $\begin{array}{l}13 \\
4\end{array}$ & $\begin{array}{l}6.7 \\
8\end{array}$ & $\begin{array}{l}4 \\
9\end{array}$ & $\begin{array}{l}4 \\
.4 \\
4 \\
8\end{array}$ \\
\hline
\end{tabular}

The comparison of PSNR of different test images for different methods and proposed filter at $90 \%$ noise density are show in following table:

Table 3: Comparison of PSNR of different test images for different methods and proposed filter of $80 \%$ impulse noise

\begin{tabular}{|c|c|c|c|c|c|c|c|c|}
\hline $\begin{array}{l}\text { Noise } \\
\text { Density } \\
\%\end{array}$ & $\begin{array}{l}\mathrm{M} \\
\mathrm{F}\end{array}$ & $\begin{array}{l}\mathrm{C} \\
\mathrm{M}\end{array}$ & $\begin{array}{l}\mathrm{DA} \\
\mathrm{M}\end{array}$ & $\begin{array}{l}\text { SA } \\
\text { W } \\
\text { M }\end{array}$ & $\begin{array}{l}\mathrm{OC} \\
\mathrm{S}\end{array}$ & $\begin{array}{l}\text { EP } \\
\text { A }\end{array}$ & $\begin{array}{l}\mathrm{AI} \\
\mathrm{M}\end{array}$ & $\mathrm{PF}$ \\
\hline Barbara & $\begin{array}{l}7 . \\
90\end{array}$ & $\begin{array}{l}22 . \\
80\end{array}$ & $\begin{array}{l}22 . \\
09\end{array}$ & $\begin{array}{l}22 . \\
96\end{array}$ & $\begin{array}{l}21 . \\
69\end{array}$ & $\begin{array}{l}23 . \\
08\end{array}$ & $\begin{array}{l}23 . \\
49\end{array}$ & $\begin{array}{l}24 . \\
86\end{array}$ \\
\hline Hill & $\begin{array}{l}8 . \\
07\end{array}$ & $\begin{array}{l}27 . \\
33\end{array}$ & $\begin{array}{l}27 . \\
12\end{array}$ & $\begin{array}{l}27 . \\
62\end{array}$ & $\begin{array}{l}26 . \\
63\end{array}$ & $\begin{array}{l}27 . \\
83\end{array}$ & $\begin{array}{l}28 . \\
51\end{array}$ & $\begin{array}{l}25 . \\
03\end{array}$ \\
\hline Boat & $\begin{array}{l}8 . \\
12\end{array}$ & $\begin{array}{l}25 . \\
63\end{array}$ & $\begin{array}{l}25 . \\
01\end{array}$ & $\begin{array}{l}25 . \\
68\end{array}$ & $\begin{array}{l}24 . \\
73\end{array}$ & $\begin{array}{l}25 \\
87\end{array}$ & $\begin{array}{l}26 . \\
57\end{array}$ & $\begin{array}{l}23 . \\
42\end{array}$ \\
\hline Baboon & $\begin{array}{l}8 . \\
15\end{array}$ & $\begin{array}{l}20 . \\
53\end{array}$ & $\begin{array}{l}20 \\
34\end{array}$ & $\begin{array}{l}20 . \\
95\end{array}$ & $\begin{array}{l}20 . \\
48\end{array}$ & $\begin{array}{l}21 . \\
30\end{array}$ & $\begin{array}{l}21 . \\
44\end{array}$ & $\begin{array}{l}21 . \\
91\end{array}$ \\
\hline Couple & $\begin{array}{l}8 . \\
19\end{array}$ & $\begin{array}{l}25 . \\
51\end{array}$ & $\begin{array}{l}25 . \\
06\end{array}$ & $\begin{array}{l}25 . \\
52\end{array}$ & $\begin{array}{l}24 . \\
87\end{array}$ & $\begin{array}{l}25 . \\
72\end{array}$ & $\begin{array}{l}26 . \\
45\end{array}$ & $\begin{array}{l}22 . \\
09\end{array}$ \\
\hline lena & $\begin{array}{l}8 . \\
14\end{array}$ & $\begin{array}{l}28 . \\
59\end{array}$ & $\begin{array}{l}27 . \\
95\end{array}$ & $\begin{array}{l}28 . \\
84\end{array}$ & $\begin{array}{l}27 . \\
95\end{array}$ & $\begin{array}{l}29 . \\
01\end{array}$ & $\begin{array}{l}29 . \\
82\end{array}$ & $\begin{array}{l}24 . \\
07\end{array}$ \\
\hline Man & $\begin{array}{l}8 . \\
08\end{array}$ & $\begin{array}{l}26 . \\
39\end{array}$ & $\begin{array}{l}26 . \\
24\end{array}$ & $\begin{array}{l}26 . \\
85\end{array}$ & $\begin{array}{l}26 . \\
06\end{array}$ & $\begin{array}{l}27 . \\
11\end{array}$ & $\begin{array}{l}27 . \\
70\end{array}$ & $\begin{array}{l}21 . \\
71\end{array}$ \\
\hline
\end{tabular}




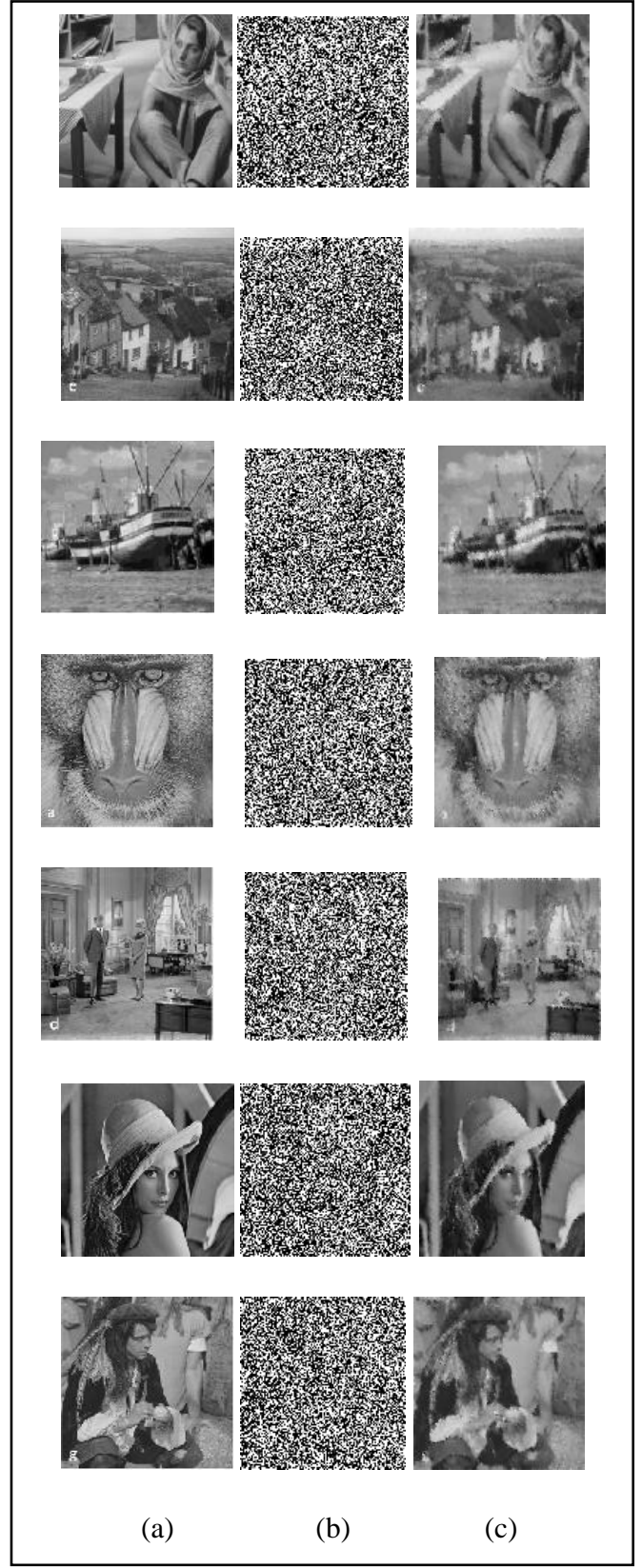

Fig 5: Result of the proposed filter on different test images at an $80 \%$ noise density. Column (a) original image (b) Corrupted image and (c) restored image using the proposed algorithm

\section{CONCLUSION}

In this paper describes a new algorithm for remove high noise density impulse noise for gray scale image. The future of new filter algorithm is used to provide a proper view to remove noise in digital image without shrinking, blurring and destroying image edges etc. Our simulation results shows more effective as compare to different existing methods. The performance parameter PSNR (Peak Signal to Noise Ratio), MSE (Mean Square Error) and CT (Computation Time) are also show better result. So we proved that new median algorithm is better for removal of impulse noise for digital images.

\section{ACKNOWLEDGMENTS}

I would like to thank to my guide Mr. Narendra Rathor, Asst. Professor Dept. of CSE and I am also thankful to Prof. Ritesh
Shah , H.O.D., Computer Science \& Engineering and dissertation Coordinator Mr. Mayank Sharma for providing me a support and proper guidance for the completion of this work.

\section{REFERENCES}

[1] Castleman Kenneth R, Digital Image Processing, Prentice Hall, NewJersey, 1979.

[2] Reginald L. Lagendijk, Jan Biemond, Iterative Identification and Restoration of Images, Kulwer Academic, Boston, 1991.

[3] Scott E Umbaugh, Computer Vision and Image Processing, Prentice HallPTR, New Jersey, 1998.

[4] Langis Gagnon," Wavelet Filtering of Speckle NoiseSome Numerical Results," Proceedings of the Conference Vision Interface 1999, TroisRiveres.

[5] A.K.Jain, Fundamentals of digital image processing. Prentice-Hall, 1989

[6] Z. Wang and D. Zhang, "Progressive switching median filter for the removal of impulse noise from highly corrupted images," IEEE Transactions on Circuits and Systems II: Analog and Digital Signal Processing, 1999, vol. 46, no. 1, pp.78-80.

[7] T. Chen and H. R. Wu, "Adaptive impulse detection using center weighted median filters," IEEE Signal Process.Lett., vol. 8, no. 1, pp. 1-3, Jan.2001

[8] S.-J. KO and Y.-H. Lee, "Centre weighted median filters and their applications to image enhancement," IEEE Trans. Circuits Syst., vol. 38, no. 9,pp. 984- 993,Sept. 1991

[9] Review of Impulse Noise Reduction Techniques Manohar Annappa Koli Research Scholar, Department of Computer Science Tumkur university.1/fnoise,"BrownianNoise,"http://classes.yale.e du/9900/math190a/OneOverF.html, 1999.

[10] Ko S.J. and Lee Y.H., "Center Weighted Median Filters and their Applications to Image Enhancement," IEEE Trans. Circuits Systems, 38, No. 9, pp. 984 - 993, 1991.

[11] Arce G. and Paredes J., "Recursive Weighted Median Filters Admitting Negative Weights and Their Optimization", IEEE Trans. on Signal Processing, 48, No. 3, pp. 768-779, 2000

[12] R. H. Chan, Chung-Wa Ho, M. Nikolova, "Salt and Pepper Noise Removal by Median Type Noise Detectors and Detail-Preserving Regularization", IEEE Transactions on Image Processing, 14 No. 10, pp. 14791485, October 2005

[13] Hani M. Ibrahem, "An Efficient and simple switching filter for removal of high density salt and pepper noise" I.J. Image ,Graphics and signal processing, published online October 2013,12,1-8 in MECS.

[14] Tao Chen, Kai-Kuang Ma, Li-Hui Chen "TriSstate Median Filter for Image Denoising" IEEE Transactions on Image Processing, Vol. 8, No. 12, December 1999, pp 1834-1838

[15] Jacques LévyVéhel, "Fraclab," wwwrocq.inria.fr/fractales, May 2000 
[16] D. L. Donoho, "De-noising by soft-thresholding", IEEE Trans. Information Theory, vol.41, no.3, pp.613- 627, May1995. Reports/1992/denoisereleas e3.ps.Z.

[17] R. Yang, L. Yin, M. Gabbouj, J. Astola, and Y. Neuvo, "Optimal weighted median filters understructural constraints," IEEE Trans. Signal Processing vol. 43, pp. 591-604, Mar. 1995.

[18] Y. Q. Dong and S. F. Xu, "A new directional weighted median filter for removal of random-valued impulse noise,'IEEE Signal Processing Letters, 2007, vol. 14, no. 3, pp. 193-196.

[19] K.S. Srinivasan and D. Ebenezer, "A new fast and efficient decision based algorithm for removal of high density impulse noise," IEEE signal process, Lett. vol.14, no.3, pp.189-192, March 2007.

[20] Kaveri A.P. and K.J.Amrutkar, "Median filtering frameworks and their application to image enhancement”, IJAIEM, volume 3, issue 3, March 2014.

[21] K. Aiswarya, V. Jayaraj, and D. Ebenezer, "A new and efficient algorithm for the removal of high density salt and pepper noise.

[22] Dr. G. Ramachandra Reddy, A. Srinivas, M. Eswar Reddy and, T.Sunilkumar "Removal of high density impulse noise through modified non linear filter"2013

[23] S. Esakkirajan, T. VeeraKumar, Adabala N. Subramanyam and C.H.Premchand,"Removal of high density salt and pepper noise through modified based asymmetric trimmed median filter", IEEE Signal processing letter,vol.18,no.5,may 2011.

[24] Dr. G. Ramachandra Reddy, A. Srinivas, M. Eswar Reddy and, T.Sunilkumar "Removal of high density impulse noise through modified non linear filter"2013

[25] H. Ibrahim, "Adaptive switching median filter utilizing quantized window size to remove impulse noise from digital images," Asian Transactions on Fundamentals of Electronics, Communication and Multimedia, 2012, vol. 2, no. 1, pp. 1-6.

[26] Z Zhou, Cognition and Removal of Impulse Noise with Uncertainty. IEEE Trans. Image Process. 21(7), 31573167 (2012)

[27] Z Deng, Z Yin, Y Xiong, High probability impulse noise-removing algorithm based on mathematical morphology, IEEE Signal Process. Lett. 14(1), 3134(2007).

[28] A Jourabloo, AH Feghahati, M Jamzad, New algorithms for recovering highly corrupted images with impulse noise. Scientia Iranica 19(6), (2012). doi:10.1016/j.scient.2012.07.016
[29] Majid, A. and Tariq Mahmood, M. “A novel technique for removal of high density impulse noise from digital images", IEEE International Conference on Emerging Technologies, ICET, Islamabad, Pakistan, pp. 139-143 (2010).

[30] PY Chen, CY Lien, An efficient edge-preserving algorithm for removal of salt-and-pepper noise. IEEE Signal Process. Lett 15, 833-836 (2008)

[31] X Zhang, Y Xiong, Impulse noise removal using directional difference based noise detector and adaptive weighted mean filter. IEEE Signal Process. Lett.16 (4), 295-298 (2009).

[32] "Fast restoration of natural images corrupted by highdensity impulse noise" Hosseini and Marvasti EURASIP Journal on Image and Video Processing 2013, 2013:15 content/2013/1/15

[33] Dodda Shekar, Rangu Srikanth, "Removal of high density salt \& pepper noise in noisy images using Decision Based Unsymmetric Trimmed Median Filter", IJCTT-vol.2, issel-2011.

[34] R. C. Hardie and K. E. Barner, "Rank conditioned rank selection filters for signal restoration," IEEE Trans. Image Processing, vol. 3, pp.192-206, Mar. 1994.

[35] Removal of high density salt and pepper noise in noisy image using Decision based unsymmetric trimmed median filter (DBUTMF) DoddaShekar\#1, Rangu Srikanth*2\#1 M.Tech in VLSI

[36] EngineeringJayamukhi Institute of Technology and Science Narsampet, Warangal, AP, India.

[37] DENG Xiuqin, XIONG and Yong PENG HONG, "A new kind of weighted median filtering algorithm used for image Processing," International Symposium on Information Science and Engineering. vol. 2, pp. 738743, Dec. 20-22, 2008

[38] "An enhanced non linear Adaptive filtering technique for removing high density salt and pepper noise "International Journal of Computer Applications (0975 8887) Volume 38- No.11, January 2012 Muhammad mizanur rahman,Faisal Ahmed

[39] Ben Hamza, P. Luque, J. Martinez, and R. Roman, "Removing noise and preserving details with relaxed median filters," J. Math. Imag. Vision, vol. 11, no. 2, pp. 161-177, Oct. 1999.

[40] V. Naga Prudhvi Raj, T. Venkateswarlu, "Denoising of Medical Images Using Dual Tree Complex Wavelet Transform", Procedia Technology, Volume 4, 2012, Pages 238-244 